\title{
Determination of Different Diseases and Preventive Measures of Mulberry Silkworm
}

\author{
Neha Singh Sisodia', S. Gaherwal ${ }^{2} *$, Renu Jain ${ }^{3}$ \\ ${ }^{1,2,3}$ Department of zoology, Govt. Holkar Science College, Indore (M.P.), India \\ *Corresponding Author: psgaherwal@yahoo.com
}

Available online at: www.isroset.org

Received: 12/Aug/2019, Accepted: 26/Aug/2019, Online: 31/Aug/2019

\begin{abstract}
The present study deals with the determination of different disease and preventive measures of mulberry silkworm, (Bombyx mori). Epizootiology, development of immunodiagnostic kit, fluorescent antibody technique and use of ideal disinfectant, chemotherapy and thermo-therapy techniques and management strategies have been addressed for identification, destruction, prevention and control of disease causing micro-organisms. Three years survey was conducted on the incidence of silkworm diseases namely, Grasserie, Flacherie, Muscardine and pebrine, the data revealed that grasserie and flacherie incidence were maximum in summer season and minimum in winter season whereas muscardine was observed high in winter.
\end{abstract}

Keywords: Bombyx mori L., Grasserie, Flacherie, Muscardine and pebrine.

\section{INTRODUCTION}

Diseases are the behavioral and physiological changes induced by pathogens in an organism. All diseases have specific symptoms and characteristics. Similarly, silkworms are also affected by various types of diseases caused by protozoa, fungi, bacteria and viruses. Since they cause substantial financial loss to the industry, their prevention and control assumes utmost importance [1].The mulberry silkworm is prone to infection of various pathogenic organisms. Infections of the disease ranging from chronic to highly virulent can result in heavy loss to the sericulture industry. Several strains and species of various micro organisms have since been isolated from the infected silkworms, and the disease is becoming increasingly more and more complex.

\section{RELATED STUDIES}

Dasgupta classified the major diseases affecting silkworm, Bombyx mori are flacherie, grasserie, muscardine and pebrine [2]. Seventy percent loss due to flacherie in sericulture industry was reported by [3] observed 30-40 per cent cocoon crop loss in silkworm is due to flacherie caused by bacteria were restricted to intestine and haemolymph. Savanurmath reported that the flacherie as the most predominant (47.9 percent) among the disease of $B$. mori followed by grasserie (42.6 percent) and kenchu [4].

\section{MATERIAL AND METHODS}

\section{Study Area}

Present work was carried out at Government Resham Kendra, Ashoknagar and Mhow (M.P.)

\section{Experimental Species}

Productive bivoltine silkworm hybrid $(\mathrm{CSR} 2 \times \mathrm{CSR} 4)$ is obtained from Central Sericulture Research and Training Institute (Mysore, India) was used as a study material. This hybrid is suitable to rear during favourable season (AugustFebruary).

\section{Rearing method}

Bombyx mori larvae (CSR2 $\times$ CSR4 strain) were reared in laboratory conditions under constant temperature $\left(25^{\circ} \mathrm{C}\right)$ and relative humidity $(75-80 \%)$.

Determination of different diseases.

The following diseases were determined in present study and identified by following scientist methods:

\section{VIRAL DISEASES}

Grasserie [5].

2. BACTERIAL DISEASES

Flacherie [6].

3. FUNGAL DISEASES

Muscardine [7].

4. PROTOZOAN DISEASE

Pebrine [8]. 
Determination and application of different drugsFollowing drugs were applied on silkworm at different stages with change in there temperature and humidity [5].

1. Methoprene

2. Fenoxycarb

3. Thiadiazole

4. Bovine milk

5. Amla extract

\section{RESULTS}

\section{DETERMINATION OF DIFFERENT DISEASES AND PREVENTIVE MEASURES OF MULBERRY SILKWORM \\ - VIRAL DISEASES \\ Grasserie}

This disease is caused by a virus.

\section{Symptoms and effects of Grasserie:}

(i) In such case of infection the larvae lose its appetite and become pale.

(ii) The body becomes swollen and shiny.

(iii) The blood of the larvae becomes turbid like pus and when the skin is broken, milky pus flows out which is known as jaundice of the silkworm.

Prevention and Control of Grasserie:

(i) The diseased larvae should be isolated from the rearing tray.

(ii) Suitable leaves, proper ventilation and spacing should be selected for the rearing of silkworm.

\section{- BACTERIAL DISEASES}

\section{Flacherie}

This disease generally occurs in the mature larvae and caused mainly by bacteria like Streptococcus and Staphylococcus.

\section{Symptoms and effects of Flacheria:}

Flacherie infected silkworm

(i) In this case there is loss of appetite in the larvae.

(ii) The larvae become sluggish and grow slowly.

(iii) The skin of larvae becomes inelastic and softening of body take place.

(iv) In the advance stage of the disease, the larvae vomit liquid material and evacuate loose bowel.

(v) The larvae become motionless, discolored and flaccid.

(vi) The body becomes black and then death occurs.

\section{Prevention and Control of Flacheria:}

(i) The diseased silkworms should be isolated from the rearing tray and then destroyed.

(ii) Maintain normal temperature, humidity and ventilation of the rearing room, supply healthy and good leaf as food, avoid overfeeding; avoid overcrowding in the rearing room etc.

\section{- FUNGAL DISEASES \\ Muscardine}

These silkworm diseases are caused by a fungus known as Beuveriabassiana.

Symptoms and effects of Muscardine:

(i) In such infection the diseased larva loses appetite.

(ii) The body of the larvae becomes stiff.

(iii) The body is covered with pale yellow powder like material.

(iv) The larvae ultimately become dead and appear like a yellow stick.

Prevention and Control of Muscardine:

(i) The infected larvae are removed and destroyed.

(ii) Good ventilation and normal humidity are to be maintained in the rearing room.

\section{- PROTOZOAN DISEASE}

Pebrine

It is a dangerous disease to the silkworms and the causative organism is the Nosemabombyc is belonging to the phylum protozoa. During the year 1865-70, this disease is first diagnosed by the great Bacteriologist Louis Pasteur. This silkworm disease is transmitted through the egg of the mother silkworm and also through ingestion of contaminated food.

\section{Symptoms and effects of Pebrine:}

Pebrine disease

(i) Infected eggs are lacking adhesive gum and so they are easily detached from the card board.

(ii) The larvae become sluggish and dull.

(iii) The larvae vomit liquid material and evacuate loose bowel.

(iv) The larvae in a rearing tray are of various sizes due to unequal growth.

(v) Infected larvae are lacking lusture.

(vi) In the advanced stage of the disease, there are irregular black spots as pepper grains on the body of the larvae. So the disease is named as pebrine.

\section{Prevention and Control of Pebrine:}

(i) After laying of eggs the female moth is crushed and the fluid of the moth is examined under the microscope; if the spores of the Nosernabombysis are observed in the fluid then all the eggs are to be destroyed to control these silkworm diseases.

(ii) Disease free eggs are dipped in a $2 \%$ formalin solution for few minutes and then washed in running water for rearing.

(iii) Disinfection of rearing room, frequent inspection of larvae in the rearing tray and destruction of diseased larvae are the general preventive measures. 


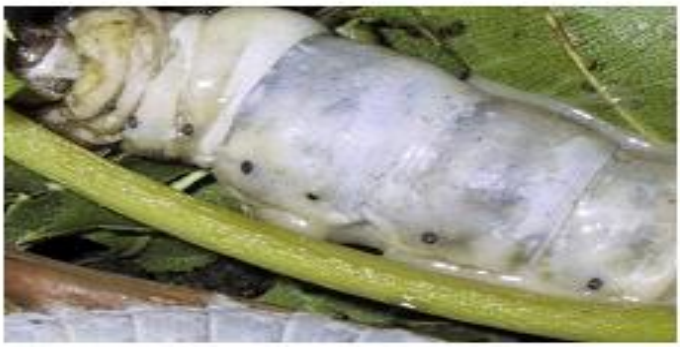

Figure-1: Grasserie

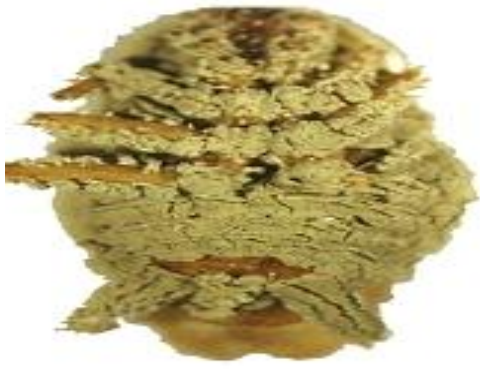

Figure-3: Muscardine.

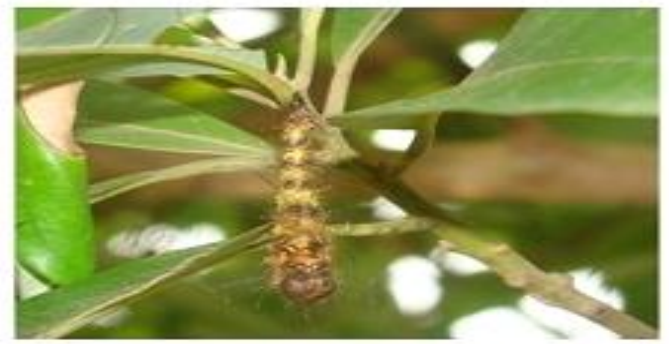

Figure-2: Flacherie.

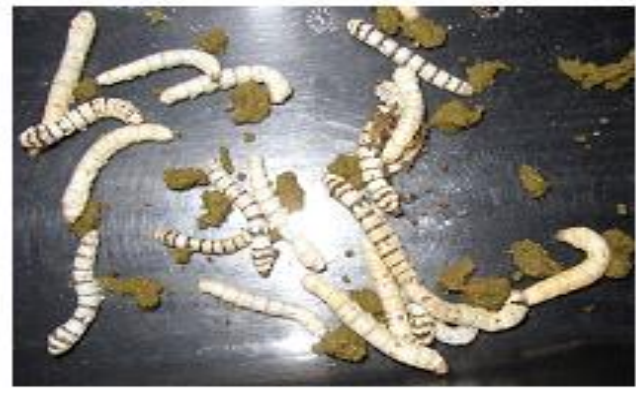

Figure-4: Pebrine.

Table-1: Impact of different drugs on healthy and diseased larvae of silk worm

\begin{tabular}{|l|c|c|c|}
\hline \multicolumn{1}{|c|}{ Drugs } & Drug concentration & No. of larvae & Diseased larvae (Survival) \\
\hline Control & - & 50 & $20 \pm 0.1846$ \\
\hline Methoprene & $1 \mu \mathrm{g}$ & 50 & $39 \pm 0.6453$ \\
\hline Fenoxycarb & $1 \mu \mathrm{g}$ & 50 & $35 \pm 0.3987$ \\
\hline Thiadiazole & Treated & 50 & $38 \pm 0.2984$ \\
\hline Bovine Milk & MTL & 50 & $40 \pm 0.6520$ \\
\hline Amla Extract & $10 \%$ (ATL) & 50 & $43 \pm 0.3523$ \\
\hline
\end{tabular}
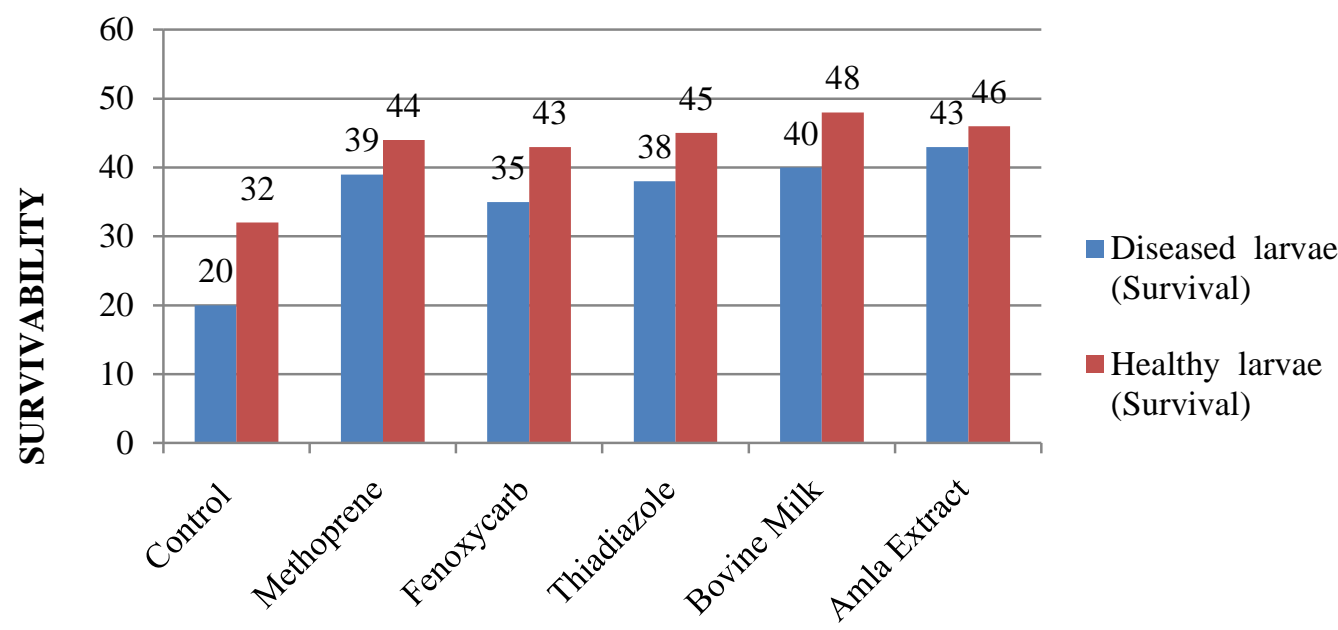

DRUGS

Figure-5: Show the impact of different drugs on healthy and diseased larvae of silk worm. 


\section{DISCUSSION}

[9] Classified the major diseases affecting silkworm, Bombyx mori are flacherie, grasserie, muscardine and pebrine. [10] Reported that the flacherie as the most predominant (47.9 per cent) among the disease of B. mori followed by grasserie (42.6 per cent) and kenchu ( 9.5 per cent) and also investigated that Streptococcus and Staphylococcus are primarily responsible for flacherie in silkworm. [11] Investigated that loss of appetite, sluggishness, flaccidity of silkworms, rapid pulsation of dorsal vessel, vomiting of brown fluid, soft excreta, decomposition of gut contents and diarrhoea are the symptoms of diseases in B. mori.

In the present investigation healthy larvae and diseased larvae of silkworm were treated with optimum concentration of different synthetic and herbal drugs (methoprene, fenoxycarb, thiadiazole, bovine milk, amla extract). The survival rate of diseased untreated (control) silkworm was 20.The maximum survival rate of silkworm was 48 and 40 for healthy and diseased larvae treated by bovine milk respectively.

Many researchers' worked on the control and prevention of disease of silkworm (flacherie, grasserie, muscardine and pebrine) during silkworm rearing helps to increase the silk productivity by preventing the mortality to a great extent. Various treatments in practice are of synthetic chemicals but no natural product has been commercialized yet. Earlier, several plants such as Lantic acid purified from Lantana camera L. had shown antibacterial activity against Bacillus cereus [12]. Garlic purified allicin also showed antibacterial action along with basil and Emblica officinalis extracts. Asparagus racemosus (wild root) found to be effective against B. subtilis, S. aureus and Pseudomonas sp. Plant extracts of Emblica officinalis, Thuja orientalis, Curcuma domestica were reported effective against $B$. thuringiensis [13].

Our study showed that the synthetic and herbal drugs have a positive effect on the health, survivability and production of $B$. mori larvae. The present study indicates that the treatment of silkworm with the synthetic and herbal drugs affects the growth, health, development of silkworm and silk productivity in comparison with the untreated ones. Thus, the results of present study also corroborated with previous researchers.

\section{CONCLUSION}

The control and prevention of various infections during silkworm rearing helps to increase the silk productivity by preventing the mortality to a great extent. In a view, use of amla extract during rearing improves the larval survival by preventing the infections and also improves the productivity of the silk.

Conclusively, use of synthetic (Methoprene, fenoxycarb and thiadiazole) and herbal drugs (bovine milk and amla extract) proves to be an growth promoter, growth enhancer and prolong the larval period of silkworm which results in the high quality of silk and good reeling performance as compared to the control ones.

\section{REFERENCES}

[1] R. Rao, "Variability in the diseases of hybrids silkworm, Bombyx mori", Journal of Sericultural Sciences, Mysore, vol. 18, no. 5, (2003), pp. 96-99.

[2] J. Das and T. Shamsuddin. Studied high temperature induced sterility in silkworm Indian Silk. J. Seric. Sci. Japan. Vol. 45, no. 3, (2006), pp. 124-130.

[3] K. Sadhu, and H. Rao. Studied tasar race-Bogai, mylitta with respect to cocoon characters and production technology. J. indust. Ent., Mysore. VOL. 67, no. 2, (2014), pp. 315-340.

[4] T. Savanurmath, and L.Sharma. Selection of diseased and healthy silkworm strain through high temperature rearing of fifth instar larvae. Central Silk, Bangalore, India. Vol. 45, no. 7, (2014), pp.234-241

[5] O. Itushi, "Silkworm nutrition on mulberry plantation in Tokyo", J. seric.sci, Jpn; vol. 48, no. 8, (2012), pp. 282- 286.

[6] A. Biram and H. Gowda, "Silkworm seed technology". In Appropriate sericulture technique Central Silk Board, Bangalore, India, vol. 89, no. 4, (2009), pp. 590 -599.

[7] H. Akai, K. Kiguchi and K. Mori, "Increased accumulation of silk protein accompanies $\mathrm{KJH}$-induced prolongation of larval life in Bombyx mori L". Applied Entomology and Zoology, vol. 67, (1971), pp. 218-220.

[8] H. Akai, K. Kiguchi and K. Mori, "Influence of thiadiazole on the growth and metamorphosis of Bombyx larvae". Bulletin of the Sericultural Experiment Station of Japan, vol. 32, (1973), pp. 287305.

[9] H. Akai and K. Kiguchi, "Ultrastructural changes of the posterior silk gland cells from the allata-ectomized 4th-instar larvae of Bombyx mori". Bulletin of the Sericultural Experiment Station of Japan, vol. 28, (1981), pp. 1-14.

[10] H. Akai, K. Kiguchi, Y. Kobari and A. Shibukawa, "Practical utilization of juvenoids for increasing silk production". Scientific Papers of the Institute of Organic Physical Chemistry, vol. 22, (1981), pp. 781-792.

[11] H. Akai, K. Kimura, M. Kiuchi and A. Shibukawa, "Effects of anti-juvenoid treatment on cocoon and cocoon filaments in Bombyx mori". Journal of Sericultural Science of Japan, vol. 53, (1984), pp. 545-546.

[12] C.F. Chang, S. Murakoshi and S. Tamura, "Giant cocoon formation in the silkworm, Bombyx mori L. topically treated with methylenedioxyphenyl derivates". Agricultural Biology and Chemistry, vol. 36, (1972), pp. 629-694.

[13] S.K. Chowdhary, F. Sehnal, S.K. Raj, P.S. Raju and S. Mathu, "Giant cocoon formation in Bombyx mori $L$. topically treated with juvenile hormone". SJ-42-F. Sericologia, vol. 26, (1986), pp. 455457. 